www.jmscr.igmpublication.org

Impact Factor (SJIF): 6.379

Index Copernicus Value: 79.54

ISSN (e)-2347-176x ISSN (p) 2455-0450

crossrefDOI: https://dx.doi.org/10.18535/jmscr/v6i12.127

Journal Of Medical Science And Clinical Research

IGM Publication

An Official Publication of IGM Publication

\title{
Comparison of Prophylactic Infusion of Phenylephrine with Ephedrine For Prevention of Hypotension in Hysterectomies Under Spinal Anaesthesia: A Randomized Clinical Trial
}

\author{
Authors \\ Dr Manoranjan Mahapatra ${ }^{1}$, Dr Aratiprava Sahu ${ }^{2 *}$ \\ ${ }^{1}$ Asst.Prof., Dept of Gynaecologic Oncology, AHRCC, Cuttack, Odisha, India \\ ${ }^{2}$ Asst. Prof., Dept of Anaesthesiology, AHRCC, Cuttack, Odisha, India \\ *Corresponding Author \\ Dr Aratiprava Sahu \\ Email:drkitusraban@gmail.com
}

\begin{abstract}
Aim: Our aim was to assess and compare the effectiveness of prophylactic infusion of ephedrine and phenylephrine given in maintenance of arterial pressure during hysterectomies under sub-arachnoid block. Methods: The present study was conducted on 80 patients undergoing elective hysterectomies under spinal anaesthesia belonging to American society of Anaesthesiologists Grade I and Grade II physical status. Group P-Phenylephrine 15 micrograms/min. Group E-Ephedrine $1.5 \mathrm{mg} / \mathrm{min}$. Haemodynamic data was collected in both the groups and observations of the analysed data are presented as mean \pm standard deviation.

Results: The prophylactic infusion of phenylephrine and ephedrine were effective in maintenance of arterial pressure within $20 \%$ limit of baseline. Additional bolus dose requirement was more in ephedrine group than phenylephrine. There was a reduction in heart rate with Phenylephrine and a rise in heart rate with ephedrine.

Conclusion: Although both drugs were effective in maintaining arterial blood pressure within normal range, Phenylephrine is more efficacious in comparison to ephedrine and additional bolus dose requirement is less with phenylephrine.

Keyword: phenylephrine, ephedrine, hysterectomies, spinal anaesthesia.
\end{abstract}

\section{Introduction}

Hypotension is the most important complication following spinal anesthesia. Prompt effective treatment is considered essential. ${ }^{1}$ Various measures are used to treat spinal induced hypotension. These include, preloading the patient with colloids or crystalloids, and use of vasopressors $^{2}$. Traditionally ephedrine has been the recommended vasopressor ${ }^{3}$. Its position has been challenged because of the potential complications that include supraventricular tachycardia, tachyphylaxis and fetal acidosis ${ }^{4}$.It is difficult to titrate and also exhibits the phenomena of tachyphylaxis due to its indirectly acting nature. ${ }^{5}$ Hence there is a need to find an alternative drug for the treatment of hypotension, which lacks the aforementioned side effects. 
Recently there has been a renewed interest in the use of phenylephrine in the treatment of hypotension during hysterectomies under spinal anasethesia $^{6}$. Phenylephrine is a directly acting sympathomimetic agent with selective alpha 1 adrenergic activity. It is easy to titrate and maintains maternal blood pressure without producing undue tachycardia.Comparative studies have shown that $\alpha$-agonist like phenylephrine is associated with better fetal acid-base status ${ }^{7}$. Phenylephrine has quicker peak effect compared to ephedrine and it causes reduction in heart rate. This study is designed to comparatively evaluate the effects of prophylactic infusion of phenylephrine and ephedrine as a vasopressor therapy in spinal anaesthesia in patients undergoing hysterectomies.

\section{Methods}

A total sample size of 80 cases were included,40 cases in each group. The sample size was calculated by assuming the power of the study to be 80 percent, Alpha value of 0.05 and difference of mean of 9 .

Sample size calculation was based on parent study

$$
\begin{aligned}
& N=\frac{\left[(Z \alpha+Z(1-\beta)]^{2} \times \sigma^{2} \times 2\right]}{d^{2}} \\
& \begin{aligned}
& Z \alpha=1.96 \quad Z \beta=0.84 \\
& \sigma=\text { pooled variance } \\
& d=\text { difference in mean }
\end{aligned}
\end{aligned}
$$

\section{Inclusion Criteria}

1. Age: $350-70 y r s$, Height: $140-170 \mathrm{cms}$.

2. ASA Grade I and II.

\section{Exclusion Criteria}

1. Patient refusal for the procedure.

2. Diabetes mellitus.

3. Patients with history of significant systemic disorders (cardiovascular, cerebrovascular, respiratory, renal, metabolic or psychiatric disorder).

4. Patients with significant coagulopathies and other contra-indications for spinal Anaesthesia.
Approval from institutional ethical committee was obtained vide IEC/IRB No. 513. The protocol was explained to all patients in detail in their own language and written informed consent for participation in the study was obtained from the patient. 80 singleton full term pregnant patients undergoing hysterectomies under subarachnoid block (SAB) were studied. They were randomly divided into two groups of 40 each, Group P (Phenylephrine group) and Group E (Ephedrine group) using computer generated randomization table. Study drugs were prepared and dispensed in infusion pumps and as bolus dose in $5 \mathrm{ml}$ syringe, labelled "Study Vasopressor" by an anaesthesiologist not involved in the study.

Phenylephrine was prepared by adding $750 \mathrm{mcg}$ in $50 \mathrm{ml} \mathrm{NS}$ i.e $15 \mathrm{mcg} / \mathrm{ml}$. Ephedrine was prepared by adding $75 \mathrm{mg}$ in $50 \mathrm{ml}$ NS i.e $1.5 \mathrm{mg} / \mathrm{ml}$. Bolus dose had $50 \mathrm{mcg} / \mathrm{ml}$ phenylephrine and $5 \mathrm{mg} / \mathrm{ml}$ of ephedrine. Preoperative evaluation of all the patients were performed with detailed history, physical examination including height, weight, and evidence of spinal deformity and mental status of the patient. All the patients were kept nil per oral for 6-8 hours. Patients were transported to the operating theatre in left lateral position.

In the operating room intravenous access was obtained by two 18 G IV cannula. Pulse oximeter, ECG and non-invasive blood pressure monitors were attached to the patient. The baseline heart rate, systolic, diastolic and mean blood pressures were measured thrice and mean value was taken as the base line value. Intravenous preloading was done with $10 \mathrm{ml} / \mathrm{kg}$ of Ringer lactate solution, given over 30 minutes.

Spinal anaesthesia was induced with patients in the lateral position under strict aseptic precautions. After skin infiltration with lidocaine, a 25-gauge Quincke needle was inserted at L3-4 vertebral interspace, and hyperbaric $0.5 \%$ bupivacaine $3 \mathrm{~mL}$ was injected intrathecally. Patients were then immediately turned supine and received oxygen at the rate of 4 Litre / min by face mask. Level of sensory block was assessed by pinprick method 5 minutes after SAB. Surgery 
was allowed to begin when the sensory level of block reached $\mathrm{T} 6$ dermatome.

Infusion of study drug was started immediately after giving spinal anaesthesia. Group P received phenylephrine $1 \mathrm{ml} / \mathrm{min}$ (15 microgram/min) and Group E received ephedrine $1 \mathrm{ml} / \mathrm{min}$. (1.5 $\mathrm{mg} / \mathrm{min}$ )After spinal anaesthesia, systolic, diastolic and mean arterial pressures were recorded every 2 minutes for 20 minutes and thereafter every 5 minutes for 1 hour. Whenever further episodes of hypotension (fall in SBP> 20\% from baseline or less than $90 \mathrm{~mm}$ of $\mathrm{Hg}$ ) occurred, the study drug was given bolus iv. Group $\mathrm{P}$ received Phenylephrine $1 \mathrm{ml}$ (50 $\mathrm{mcg}$ ) and Group E received $1 \mathrm{ml}(5 \mathrm{mg})$ Ephedrine as intravenous rescue bolus. Whenever any episodes of hypertension occurred (rise in SBP>30\% from baseline), infusion of study drug was stopped until the SBP was restored to baseline. Bradycardia was defined as heart rate $<60 \mathrm{bpm}$ and was treated with $0.6 \mathrm{mg}$ of intravenous atropine. The patients were monitored for any bradycardia, reactive hypertension, nausea, vomiting. Number of rescue boluses administered were also noted.

Statistical Analysis

Data entered in Microsoft Excel Statistical analyisis was done using SPSS Ver.17. Quantitative variables described by mean, sd, minimum and maximum. Qualitative variables described by percentage distribution. Between group comparison of quantitative variables were done by independent sample $t$ test and that of the qualitative variables by Chi- square test. A p value of 0.05 is taken as the level of significance

\section{Results}

The present study was conducted on 80 patients undergoing elective hysterectomies under spinal anaesthesia belonging to American society of Anaesthesiologists Grade I and Grade II physical status. Each group consisted of 40 patients and were divided as Group P (Phenylephrine group, $n$ $=40$ ) and Group E (Ephedrine group, $n=40$ ) by a computer generated randomization table. Data was collected in both the groups and observations of the analysed data are presented as mean \pm standard deviation in the tabular form. The age, weight, height were comparable in both the groups.

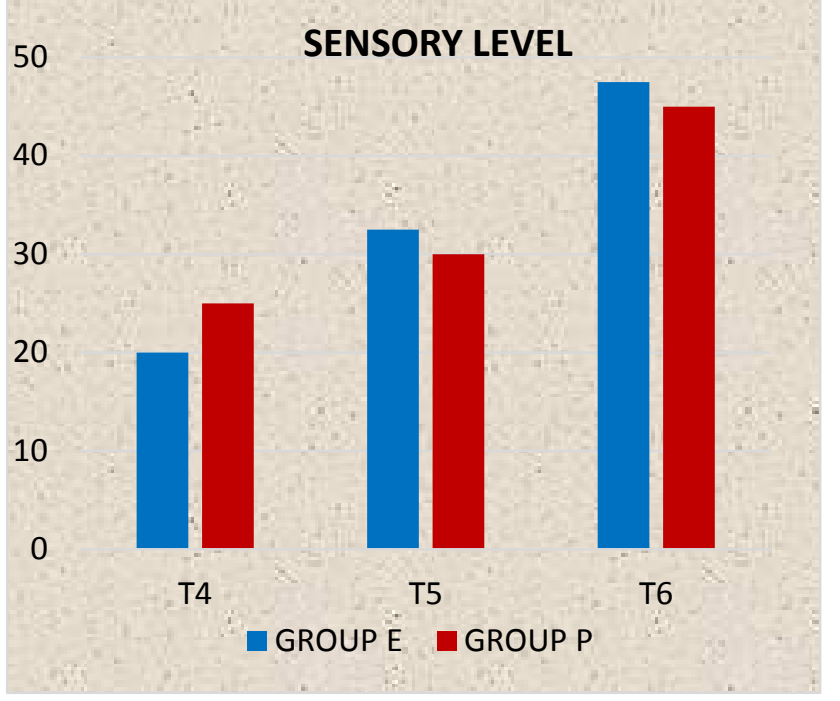

Figure 1: Comparison of sensory levels between two groups

Level of sensory blockade after $5 \mathrm{~min}$ of $\mathrm{SAB}$ in both the groups were comparable. (fig-1)

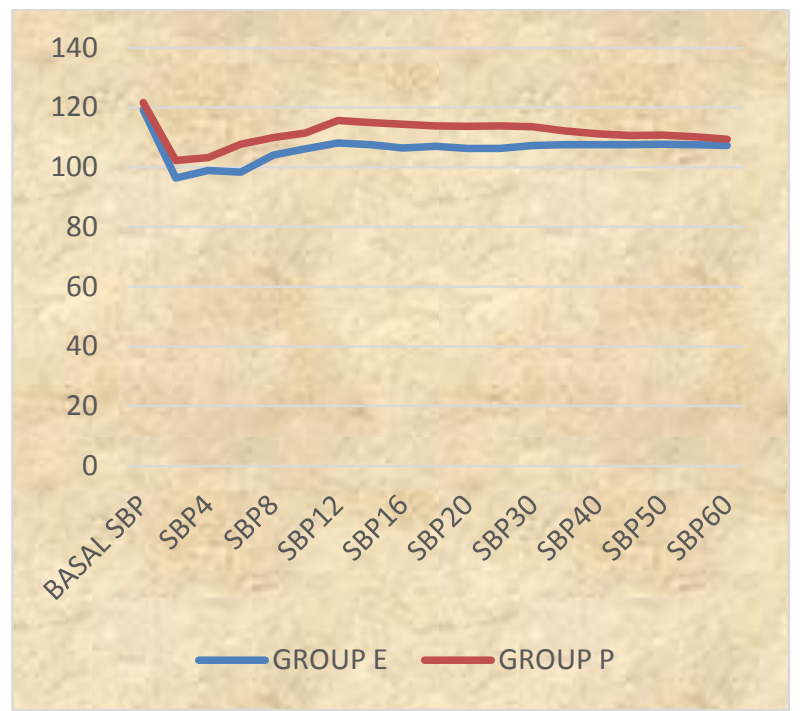

Figure 2: Changes in systolic pressures in both groups

Basal SBP in Phenylephrine group was $119.3 \pm 8.2$ and that in Ephedrine group was $121.7 \pm 8.8 \mathrm{~mm}$ of $\mathrm{Hg}$. They are comparable statistically. (fig-2) But Systolic blood pressure remains high in Phenylephrine group compared to Ephedrine group throughout the observation period. 


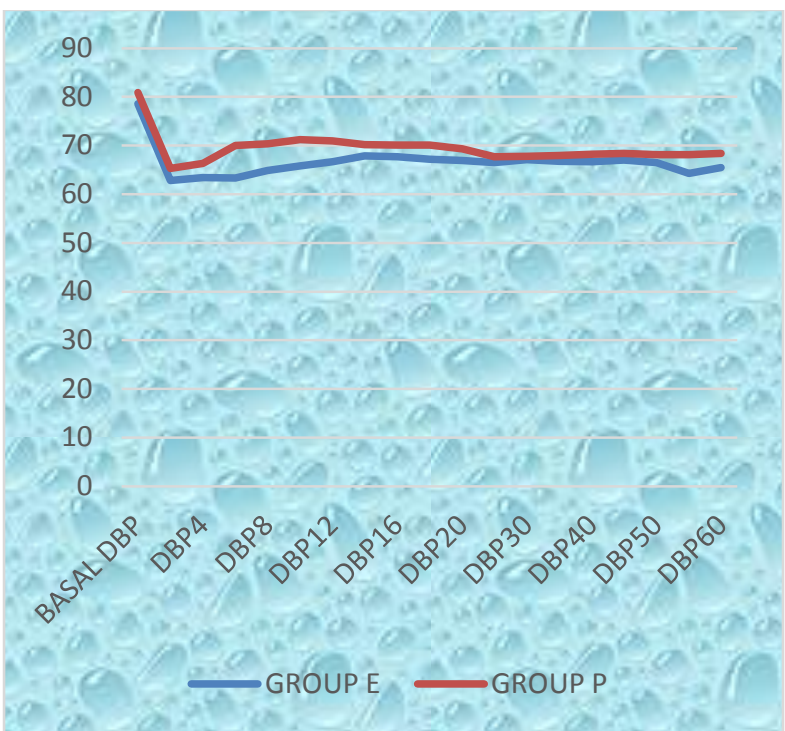

Figure 3: Intraoperative changes in diastolic blood pressure in Group P and E

Basal DBP were statistically comparable in both the groups. But diastolic blood pressure was well maintained with phenylephrine group than ephedrine group. (fig-3)

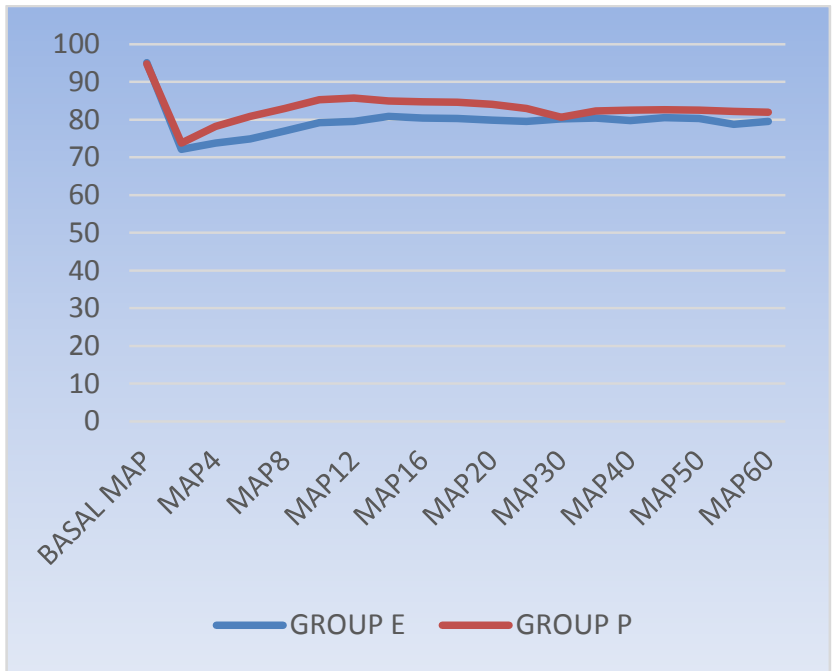

Figure 4: Intraoperative changes in Mean arterial pressure in Group $\mathrm{P}$ and $\mathrm{E}$

Basal MAP and MAP intraoperatively were statistically comparable in both the groups. (fig-4)

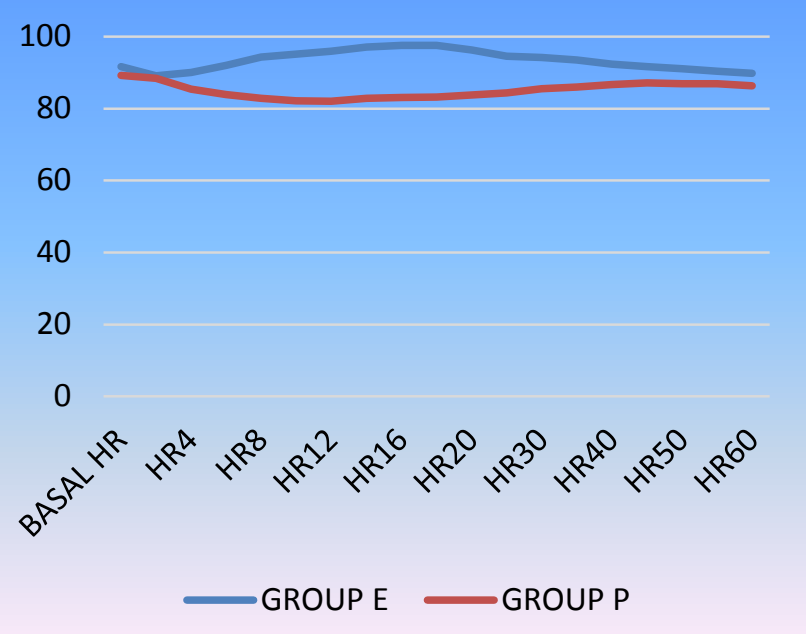

Figure 5: Changes in heart rate in both groups Phenylephrine group shows a significant fall in HR while in Ephedrine group there is a significant rise in the HR.(fig-5) 35 patients in both the groups developed hypotension and required additional vasopressor treatment. According to table 1 , incidence of hypotension was more in ephedrine group than phenylephrine group and additional dose requirement (second, third and fourth) was higher in ephedrine group ( $p$ $<0.0001)$. Out of 9 patients requiring 3 rescue bolus doses, 6 patients were from ephedrine group (66.6\%) and 3 patients from phenylephrine group (p <0.001). (table 1)

Table 1: Number of additional vassopressor requirement for treatment of hypotension

\begin{tabular}{|l|c|c|c|c|}
\hline $\begin{array}{l}\text { Additional } \\
\text { vasopressor }\end{array}$ & Total & $\begin{array}{c}\text { Group E } \\
(\mathrm{N}=40)\end{array}$ & $\begin{array}{c}\text { Group P } \\
(\mathrm{N}=40)\end{array}$ & $\begin{array}{c}\mathrm{P} \\
\text { value }\end{array}$ \\
\hline $\begin{array}{l}\text { Without } \\
\text { additional } \\
\text { vasopressor }\end{array}$ & 35 & $9(25.7 \%)$ & $26(74.28 \%)$ & 0.0001 \\
\hline 1 Dose & 16 & $10(62.5 \%)$ & $6(37.5 \%)$ & 0.003 \\
\hline 2 Doses & 17 & $12(70.5 \%)$ & $5(29.5 \%)$ & 0.001 \\
\hline 3 Doses & 9 & $6(66.66 \%)$ & $3(33.33 \%)$ & 0.001 \\
\hline 4 Doses & 3 & $3(100 \%)$ & 0 & 0.049 \\
\hline
\end{tabular}

In the present study, none of the patients had nausea or vomiting in both groups.

\section{Discussion}

The most common side effect following spinal anaesthesia is hypotension ${ }^{7}$. Prevention and treatment of hypotension remains a frequent problem with no consensus in the optimal mode of management. Fluid preloading with intravenous crystalloid or colloid solutions is a standard 
practice for prevention of hypotension but it has been found to be ineffective if used alone, without concomitant use of vasopressor drugs. There have been several attempts to find the optimal therapy for hypotension. Since sympathetic blockade resulting in vasodilatation is the primary cause of fall in arterial pressure, use of vasopressors in conjunction with fluid preloading appears to be a more logical approach to correct it. Hypotension in most of the studies has been defined as values ranging from 20 to 30 percent reduction from baseline systolic arterial pressure or mean arterial pressure $^{8}$. In our study we defined hypotension as decrease in systolic arterial pressure 20 percent from the baseline systolic pressure. We defined bradycardia as heart rate of less than 60 per minute. The role of intravenous vassopressors has been well established in case of postspinal hypotension. Ephedrine acts directly as well as indirectly on alpha and beta adrenergic receptors. Phenylephrine has selective alpha adrenergic activity due to which it was considered to cause reduction in uterine blood flow, but it has been mentioned that Phenylephrine causes less foetal acidosis than Ephedrine in a review by Ngan et $\mathrm{al}^{9}$.In our study both the vasopressors maintained arterial blood pressure within 80percent of limit of baseline value, although Phenylephrine maintained a better blood pressure than Ephedrine. These results correlate with a previous study conducted by Sahu et al. ${ }^{14}$ In our study we also found that both the drugs maintained systolic, diastolic and mean arterial pressure, but ephedrine group required more additional bolus doses than phenylephrine group. (P value <0.001) Probably, tachyphylaxis related to repeated doses or continuous infusion of ephedrine was responsible for these findings.In our study, a significant reduction in heart rate after Phenylephrine infusion was observed which may be attributed to positive inotropic and negative chronotropic effect of Phenylephrine. This has been consistent effect in other studies also. In the study by Moran DH et al ${ }^{10}$ there was significant bradycardia which was treated with Atropine. Similarly, Thomas DG et al
${ }^{11}$ showed $58 \%$ incidence of bradycardia (defined as heart rate below 60 beats per minute) when 100 mcg of Phenylephrine was given as intravenous bolus after induction of spinal anaesthesia. In our study although there was a fall in heart rate, after administration of Phenylephrine, but it was not significant enough to warrant treatment. This can be attributed to less dose of drug administered. In Ephedrine group, the heart rate increased after the infusion, compared to the pre - drug administration values which we found statistically significant and the data was consistent with study of Sahu et al. ${ }^{14}$ This tachycardia may be attributed to beta adrenergic effect of Ephedrine which Phenylephrine lacks.

The use of $\alpha$-agonists has generally been avoided since the 1970s because of concerns about their potential adverse effect on uterine blood flow. However, in a quantitative, systematic review of randomized controlled trials of ephedrine versus phenylephrine for the management of hypotension during spinal anesthesia for cesarean delivery, Lee and colleagues $^{12}$ showed that there was no difference between ephedrine and phenylephrine in efficacy. They did find, however, that women given phenylephrine had neonates with higher umbilical cord blood $\mathrm{pH}$ values than women given ephedrine, although the risk of true fetal acidosis (umbilical $\mathrm{pH}$ value of 7.20) was similar in both groups. Because acidotic changes in the umbilical arterial $\mathrm{pH}$ are sensitive indicators of reduced uteroplacental perfusion, the authors concluded that their finding was indirect evidence that uterine blood flow may be better with phenylephrine compared with ephedrine. In addition, a meta-analysis by Reynolds et al ${ }^{13}$ showed that spinal anesthesia for cesarean delivery is associated with lower cord $\mathrm{pH}$, compared with general or epidural anesthesia. They suggested that the use of larger doses of ephedrine in patients who received spinal anesthesia largely contributed to these findings. There are two reasons why phenylephrine may be associated with a better fetal acid-base status than ephedrine. First, ephedrine readily crosses the 
placenta and has been shown to increase fetal heart rate. Ephedrine may also stimulate fetal metabolism by a direct $\beta$-adrenergic effect as well as by stimulating endogenous release of fetal catecholamines. Thus, a direct metabolic effect on the fetus is a likely explanation for the acidosis associated with the use of ephedrine. The second possible explanation for improved fetal acid-base status with phenylephrine compared with ephedrine is that the sympathectomy resulting from regional anesthesia shunts blood into the mesenteric bed and that $\alpha$-agonists like phenylephrine have a greater selective vasoconstrictive effect on the mesenteric bed than on the uteroplacental vasculature.

Vasoconstriction in the mesenteric bed increases cardiac preload, which allows for improved uteroplacental perfusion.Use of Phenylephrine in pregnant patients has always been an issue of debate and controversy, because of its alpha effect causing placental vasoconstriction. In a recent metanalysis by Ngan et $\mathrm{al}^{15}$ Phenylephrine was suggested to be the ideal agent for hypotension caused by spinal anaesthesia. Other studies using Phenylephrine in pregnant patients have found that although it causes foetal acidosis, it's less than that caused by Ephedrine and is non detrimental to neonatal outcome.

\section{Conclusion}

From our study we concluded that, prophylactic Phenylephrine in a dose of $15 \mathrm{microgram} / \mathrm{min}$ is more efficacious in comparison to Ephedrine 1.5 milligrams/min in maintaining arterial blood pressure following spinal anaesthesia for hysterectomies. Additional bolus dose requirement is more with ephedrine than phenylephrine.

\section{References}

1. Mercier FJ, Riley ET, Fredericson WL, RogerChristoph S, Benhamou D, Cohen SE. Phenylephrine added to prophylactic ephedrine infusion during spinal anaesthesia forelective

Caesarean

section.

Anaesthesiology 2001; 95: 668-74.

2. NganKee WD, Lee A. Multivariate analysis of factors associated with umbilicalarterial $\mathrm{pH}$ and standard base excess after Caesarean section under spinalanaesthesia. Anaesthesia. 2003 Feb;58(2):125-30.

3. NganKee WD, Khaw KS, Ng FF. Comparison of Phenylephrine infusion regimens for maintaining maternal blood pressure during spinal anaesthesia forCaesarean section. $\mathrm{Br} \mathrm{J}$ Anaesth. 2004 Apr;92(4):469-74.

4. NganKee WD, Khaw KS, Ng FF: Prevention of hypotension during spinal anaesthesiafor caesarean delivery: An effective technique using combination phenylephrineinfusion and crystalloid cohydration. Anaesthesiology, 2005; 103: 744-50.

5. Sarvanan, MKocarev R. C. Wilson E. Watkins et al. Equivalent dose ofephedrine and phenylephrine in the prevention of post-spinal hypotension incaesarean section. British J. of Anaesthesia 2006(1):95-9.

6. NganKee WD, Khaw KS. Vasopressors in obstetrics: what should we be using? Curr Opin Anaesthesiol. 2006 Jun;19(3):238-43.

7. NganKee WD, Lee A, Khaw KS, Ng F, Karmakar MK, Gin T. A RandomizedDoubleBlinded Comparison of phenylephrine and ephedrine Infusion Combinationsto maintain blood pressure during spinal anaesthesia for caesarean delivery: The effectson foetal acidbase status and hemodynamic control. AnesthAnalg2008;107:1295-1302

8. Cooper DW, Carpenter M, Mowbray P, Desira WR, Ryall DM, Kokri MS. Foetaland maternal effects of Phenylephrine and ephedrine during spinal anaesthesia for caesarean delivery. Anaesthesiology. 2002 Dec;97(6):1582-90.

9. Ngan Kee WD, Khaw KS, Lee BB, et al: A dose-response study of prophylactic ephedrine for the prevention of hypotension during spinal anesthesia for cesarean delivery. Anesth Analg 2000; 90:1390-1395. 
10. Moran D. H, Perillo M, LaPorta R F, Bader AM, Datta S. Phenylephrine in theprevention of hypotension following spinal anaesthesia for caesarean delivery. JClinAnesth. 1991 julAug; 3(4):301-5.

11. Thomas DG, Robson SC, Redfern N, Hughes D, Boys RJ. Randomized trial ofbolus Phenylephrine or ephedrine for maintenance of arterial pressure duringspinalanesthesia for Caesarean section. $\mathrm{Br}$ J Anaesth. 1996 Jan;76(1):61-5

12. Lee A, NganKee WD, Gin T. A quantitative, systematic review of randomizedcontrolled trials of ephedrine versus Phenylephrine for the management ofhypotension during spinal anaesthesia for caesarean delivery. AnesthAnalg. 2002 Apr;94(4):920-926.

13. Reynolds F, Seed PT: Anesthesia for caesarean section and neonatal acid-base status: A meta-analysis. Anesthesia 2005; 60:636-653.

14. Sahu D, Kothari D, Mehrotra A. Comparison of bolus Phenylephrine, ephedrine, and Mephentermine for maintenance of arterial pressure during spinal anaesthesiain caesarean section- a clinical study. Indian J Anaesthesia. 2003;47(2): 125-128.

15. NganKee W. D, Khaw K. S, Lau T. K, F. F. Ng, K. Chui, K.L. Ng. Randomizeddouble blinded comparison of Phenylephrine Vs Ephedrine for maintaining bloodpressure during spinal anaesthesia for non- elective caesarean section. Anaesthesia, 2008,63:131913263. 